\title{
PERFORMANSI DAN GRAMATIKA BAHASA ARAB SEBAGAI BAHASA KEDUA
}

\author{
Ulil Albab \\ Universitas Islam Negeri Raden Fatah Palembang \\ e-mail : ulilalbab671@gmail.com
}

Naskah diterima: 26 Februari 2015, direvisi: 30 April 2015, disetujui: 2 Mei 2015.

\begin{abstract}
Grammar is one of the important components in studying a language. It is related to stimulate language skills includes: listening, reading, speaking, and writing. This article discusses the teaching of grammar in pesantren. The pesantren used salafiyah and modern curriculum. The study is conducted for 22 students in the last class. The method used is a correlational study. The result of the study shows that there is a positive correlation between grammatical mastery and language performance in teaching \& learning Arabic. Means that grammatical mastery is one of the important factors to perform a good Arabic language.
\end{abstract}

Keywords : grammatical mastery, language performance, salafiyah curriculum, modern curriculum

\section{Abstrak}

Problem utama yang didiskusikan dalam tulisan ini adalah anggapan bahwa pengajaran gramatika didalam kelas merupakan suatu yang tidak mempunyai kontribusi dalam pembelajaran bahasa kedua. Tulisan ini telah meneliti 22 orang peserta didik kelas akhir pada pesantren yang mengombinasikan kurikulum salafiyah dan modern. Hasil penelitian didapatkan bahwa pembelajaran gramatika secara formal mempunyai hubungan terhadap kemampuan performansi bahasa. Implikasi dari tulisan ini diharapkan agar pembelajaran gramatika secara formal bukan hanya sebagai warisan sekolah atau sekedar budaya. Kemampuan pembelajaran gramatika dapat memperbaiki performansi bahasa pembelajar bahasa kedua baik lisan maupun tulisan.

Kata Kunci : gramatika bahasa, performansi bahasa Arab, kurikulum salafiyah, kurikulum modern

How to Cite : Albab, Ulil. "PERFORMANSI DAN GRAMATIKA BAHASA ARAB SEBAGAI BAHASA KEDUA" ARABIYAT : Jurnal Pendidikan Bahasa Arab dan Kebahasaaraban [Online], Volume 2 Number 1 (30 Juni 2015)

Permalink/DOI: http://dx.doi.org/10.15408/a.v2i1.1516 


\section{Pendahuluan}

Pembelajaran gramatika membekali peserta didik dengan kaidah-kaidah kebahasaan yang memungkinkannya dapat menjaga bahasanya dari kesalahan. Ringkasnya adalah mengenalkan dan membiasakan peserta didik menggunakan kaidah-kaidah nahw dan șarf secara tepat, sehingga terhindar dari kesalahan lisan, kesalahan baca, dan kesalahan dalam ekspresi tulisan. ${ }^{1}$ Menurut Ruthefod bahwa gramatika digunakan untuk menganalisis sistem bahasa. Pembelajaran gramatika tidak hanya dianggap penting pada fitur pembelajaran bahasa, akan tetapi dianggap cukup membantu peserta didik untuk benar-benar menguasai bahasa asing yang lainnya. ${ }^{2}$

Dengan begitu kedudukan gramatika sebagai komponen penting dalam ilmu bahasa bukanlah merupakan suatu yang sia-sia. Gramatika mempunyai peran dalam setiap pembicaraan yang keluar dari lisan pembicara untuk dimengerti ucapannya kepada lawan bicara. Kompetensi gramatika menempati posisi yang sangat menonjol dan utama dalam kemampuan berkomunikasi. Peran gramatika ini dalam perkembangan bahasa didukung secara teoritik dan empirik. $^{3}$

Skinner dalam karya monumentalnya Verbal Behavior meneliti seekor tikus yang akhirnya memperoleh pengetahuan. Proses

1 Fakhr al-Din Amir dalam Muhbib Abdul Wahab, Epistemologi \& Metodologi Pembelajaran Bahasa Arab (Jakarta: Lembaga Penelitian Universitas Islam Negeri Syarif Hidayatullah Jakarta, 2008), h. 174.

2 Ruthefod dalam James Purpura, Assessing Grammar (Australia: Cambridge University Press, 2004), h. 1.

3 Ellis, James Scott dalam Abdulmoneim Mahmoud, "Learner Involvement in Language Development: From Course Design to Performance Assessment", Journal of Language Teaching and Research, Vol. 4, No. 4, July 2013 (accessed October 30, 2013) yang dinamakan operant conditioning ini melatih tikus untuk memperoleh makanan dengan menekan suatu pedal. ${ }^{4}$ Dari eksperimen ini Skinner menyimpulkan bahwa pemerolehan pengetahuan termasuk pengetahuan pe-makaianbahasadidasarkan pada adanya stimulus dan diikuti oleh respon. Dari proses ini akan muncullah kebiasaan. ${ }^{5}$

Pandangan ini berpendapat semua keterampilan manusia diperoleh dengan proses belajar, dan manusia sejak lahir telah dilengkapi dengan kemampuan belajar. Ini mengisyaratkan bahwa bahasa harus dipelajari karena kemampuan berbahasa adalah kemampuan hasil belajar dan bukan diwariskan. ${ }^{6}$

Pada 1959 Chomsky menulis resensi yang secara tajam menyerang teori Skinner yang mengatakan bahwa pada dasarnya bahasa itu bukan didasarkan pada nature tetapi pada nurture. ${ }^{7}$ Menurut Chomsky, manusia mempunyai faculty of the mind semacam kapling-kapling intelektual dalam otaknya. Kapling kodrati yang dibawa sejak lahir disebut dengan Language Acquisition Device (LAD). ${ }^{8}$ Hipotesis Chomsky ini dinamakan pula dengan hipotesis nurani. Hipotesis ini menyatakan bahwa otak manusia dipersiapkan secara genetik untuk berbahasa. ${ }^{9}$

4 B. F. Skinner, Verbal Behavior (Harvard: Harvard University, 1948) (accessed July 04, 2014)

5 Soenjono Dardjowidjojo, Psikolinguistik Pengantar Pemahaman Bahasa Manusia (Jakarta: Yayasan Obor Indonesia, 2010), h. 235.

6 Jos Daniel Parera, Linguistik Edukasional Metodologi Pembelajaran Bahasa Analisis Konstranstif Antarbahasa Analisis Kesalahan Berbahasa (Jakarta: Erlangga, 1997), h. 51.

7 Soenjono Dardjowidjojo, Psikolinguistik Pengantar Pemahaman Bahasa Manusia, h. 236.

8 Noam Chomsky, On Nature and Language (Cambridge: Cambridge University Press, 2002), h. 1 .

$9 \quad$ Abdul Chaer, Psikolingustik Kajian Teoritik (Jakarta: Rineka Cipta, 2009), h. 108. 
Begitu juga pada waktu lahir anakanak telah dikaruniai dengan seperangkat tata bahasa yang bersifat universal dan kemudian lingkungan yang akan menentukan dimana bahasa itu akan diwujudkan. ${ }^{10}$ Dapat disimpulkan bahwa pembelajaran tata bahasa telah ada dalam konsep otak manusia sehingga menurut Krashen pembelajaran tata bahasa ini tidak perlu diajarkan dalam pembelajaran bahasa khususnya pada bahasa kedua. ${ }^{11}$

Kedua teori di atas masing-masing mempunyai kelebihan dan kekurangan. Tuhan telah mempersiapkan kepada manusia sejak lahir sebuah alat agar manusia dapat berbahasa, namun jika kemampuan berbahasa tersebut tidak dipelajari maka manusia tidak bisa berbahasa.

Dalam pembelajaran bahasa kedua atau bahasa asing khususnya gramatika tidak bisa didapatkan begitu saja secara alami, akan tetapi perlu diajarkan. Jianyun Zhang berpendapat bahwa gramatika adalah sesuatu yang penting, gramatika tidak diperoleh secara alami dan perlu diajarkan. ${ }^{12}$

Tulisan ini membuktikan bahwa pembelajaran gramatika secara formal bukanlah suatu yang sia-sia. Hal ini dapat dilihat melalui keterampilan memproduksi bahasa (performance language). Memperkuat pernyataan Dulay dkk bahwa pembelajaran gramatika secara formal dapat memperbaiki kualitas performansi bahasa peserta didik. ${ }^{13}$

10 Elizabeth Bates, “On The Nature and Nurture of Language" (San Diego: University of California) (accessed July 03, 2014)

11 Lihat Stephen D Krashen, "The Effect of Formal Grammar Teaching: Still Peripheral" TESOL QUARTERLY Volume 27, No.4 (Winter 1993) (accessed July 1, 2013).

12 Jianyun Zhang, "Necessity of Grammar Teaching" International Education Studies Vol. 2 No. 2 (May 2009) (accessed May 21, 2013)

13 Lihat Abdul Chaer, Psikolingustik Kajian Teoritik, h. 255.

\section{Metode Penelitian}

\section{Jenis Penelitian}

Penelitian ini termasuk penelitian kuantitatif dengan jenis kuantitatif korelasional. Penelitian kuantitatif adalah melihat suatu realitas sebagai hal yang tunggal teramati dan dapat dipragmentasikan sehingga masalah yang ada dapat menggenalisir dan memprediksi suatu masalah berdasarkan sejumlah variabel prediktor. Penelitian kuantitatif berangkat dari teori ke lapangan dan kembali lagi ke teori untuk diuji kebenarannya. ${ }^{14}$

\section{Subjek Penelitian}

Subjek penelitian ini adalah seluruh peserta didik kelas akhir. Alasan pengambilan subjek penelitian ini bahwa peserta didik kelas akhir sudah banyak mempelajari mata pelajaran gramatika bahasa Arab dimulai dari kelas VII Madrasah Tsanawiyah. Karena pesantren ini resmi dibangun pada tahun 2007, maka yang dimaksudkan kelas akhir di sini adalah peserta didik kelas sebelas yang merupakan angkatan pertama pada pondok pesantren tersebut.

\section{Populasi dan Sampel Penelitian}

Populasi adalah seluruh subyekyang dijadikan sasaran penelitian. Menurut Arikunto populasi adalah keseluruhan subjek penelitian. Apabila ingin meneliti semua elemen yang ada, maka penelitiannya merupakan populasi studi atau populasi studi sensus. ${ }^{15}$

14 Abdul Halim Hanafi, Metodologi Penelitian Bahasa untuk Penelitian Tesis, dan Disertasi, (Jakarta: Diadit Media Press, 2011), h. 84.

15 Suharsimi Arikunto, Prosedur Penelitian (Suatu Pendekatan Praktik), (Jakarta: Rineka Cipta, 2006) 130. 
Adapun jumlah populasi peserta didik di pondok pesantren tersebut adalah sebagai berikut:

\begin{tabular}{|c|c|c|c|}
\hline No & Kelas & Putra & Putri \\
\hline $\mathbf{1}$ & VII & 47 Orang & 29 Orang \\
\hline $\mathbf{2}$ & VIII & 26 Orang & 24 Orang \\
\hline $\mathbf{3}$ & IX & 25 Orang & 21 Orang \\
\hline $\mathbf{4}$ & X & 6 Orang & 20 Orang \\
\hline $\mathbf{5}$ & XI & - & 22 Orang \\
\hline & Jumlah & 104 Orang & 116 Orang \\
\hline
\end{tabular}

Pengambilansampel pada penelitian ini menggunakan teknik purposive sampling. Teknik penarikan sampel ini dilakukan berdasarkan karakteristik yang ditetapkan terhadap elemen populasi target yang disesuaikan dengan tujuan atau masalah penelitian.

Sampel yang dipilih adalah peserta didik kelas akhir dengan alasan pengambilan sampel adalah bahwa peserta didik kelas akhir tersebut telah banyak mendapatkan materi pelajaran gramatika dimulai dari kelas VII Madrasah Tsanawiyah, maka sampel penelitian ini berjumlah 22 orang peserta didik kelas akhir yang masih duduk di kelas XI Madrasah Aliyah.

\section{Sumber Data}

Sumber data dalam penelitian ini meliputi sumber data primer dan sekunder.

Data primer diperoleh dari peserta didik kelas sebelas, wawancara guru bidang studi, observasi pesantren, dan dokumen-dokumen yang ada disekolah.

Data sekunder diperoleh dari berbagai sumber tertulis atau kepustakaan baik laporan kajian-kajian terdahulu berupa: disertasi, tesis, jurnal-jurnal dalam bentuk cetakan atau elektronik yang berbicara tentang tema yang sama, serta sumber, dokumen dan data penunjang lainnya.

\section{Teknik Pengumpulan Data}

Dalam hal ini peneliti melakukan teknik pengumpulan data sebagai berikut:

a). Tes

Tes performa ini untuk mengukur kompetensi gramatika pada kemampuan performansi berbicara bahasa Arab. Dalam penelitian ini peneliti mengambil penilaian hasil. Penilaian hasil di sini adalah peserta didik telah mendapat mata pelajaran gramatika.

b). Kuisioner

Kuisioner untuk melihat sikap dan motivasi peserta didik dalam mempelajari gramatika bahasa Arab selama proses pembelajaran berlangsung.

c). Observasi

Observasi ini untuk melihat kegiatan-kegiatan peserta didik dalam bidang kebahasa araban dan kegiatan belajar mengajar.

d). Dokumentasi

Dokumentasi ini berupa daftar nilai gramatika yaitu nilai harian, ujian tengah semester, ujian praktek dan ujian akhir semester.

\section{Analisis Data}

Analisis data, merupakan upaya yang dilakukan untuk mengaklasifikasi, mengelompokkan data. Pada tahap ini dilakukan upaya mengelompokkan, menyamakan data yang sama dan membedakan data yang berbeda serta menyisihkan pada kelompok lain data yang serupa, tetapi tak sama. ${ }^{16}$

a). Teknik Analisis Data: teknik analisa data dilakukan dengan uji

16 Mahsun, M. S, Metode Penelitian Bahasa Tahapan Strategi, Metode, dan Tekniknya (Jakarta: PT Raja Grafindo Persada, 2007), h. 253. 
$\mathrm{T}$ Independen untuk signifikansi koefesien korelasi.

UjiTadalahujistatistikuntukmelihat hubungan antara variabel dependen yang berjenis kategorik dengan variabel independen yang berjenis numerik. Variabel dependen adalah pembelajaran gramatika yang hasil ukurnya kategorik (tinggi rendah), adapun variabel independen adalah skor performa gramatika dengan hasil ukur berupa numerik (nilai).

b). Teknik analisis statistik menggunakan uji $\mathrm{T}$ parametrik dan uji nonparametrik (mann whitney). Uji T parametrik digunakan apabila data variabel skor berdistrubusi normal. Sedangkan uji $\mathrm{T}$ nonparametrik digunakan apabila data variabel skor tidak berdistribusi tidak normal.

Uji Persyaratan Analisis: Uji persyaratan analisis yang dilakukan adalah uji normalitas skor dengan menggunakan uji kolmogorovsmirnov, data berdistribusi normal jika Pvalue $>0,05$.

\section{Pembahasan}

Menurut Ibn Khaldun, aturan gramatika merupakan salah satu tahapan yang paling menonjol pada pembelajaran bahasa Arab. Dia memposisikan gramatika pada baris depan dalam imu lisan. ${ }^{17}$ Menurut Amin alKukhun gramatika merupakan sebuah jalan untuk memperbaiki lisan dan menjaganya dari kesalahan lafal. ${ }^{18}$ Brown berpendapat

\footnotetext{
17 Bulkhair Shinin, "Turuqu Tadrîs al-Qawâ'id an-Naḥwiyah wa 'Alaqatuhâ bi Fikri Ibnu Khaldûn”, Majalah al-Athar, al-'Adad 13 / Māris 2012, (dikases 20 Oktober 2013)

18 Amin al-Kukhun dan Linâ Haniyah, "Atharu Istikhdam ad-Dirâma at-Ta'lîmiyah fî Tadrîsi Qawâ'id al-Lughah al-'Arabiyah fi Tahșili Ṭâlibâh aș-Ṣafi alÂshir al-Asâsî”, Majallah al-Urduniyah fî 'Ulumi at-
}

bahwa pengajaran gramatikasecaraeksplisit lebih efektif untuk tingkat intermediate sampai tingkat advanced keatas. ${ }^{19}$

Pada pembelajaran gramatika buku yang dipakai di pesantren ini adalah alKawâkib ad-Dâriyah buku ini sering dipakai pada pesantren salafiyah. Kemampuan peserta didik dalam pelajaran gramatika yang diselenggarakan selama satu semester maka didapatkan nilai kumulatif berdasarkan perhitungan guru bidang studi adalah $92-100=$ A, 83-91 = B, 74-82 = C. Jika dijadikan dalam bentuk diagram seperti berikut:

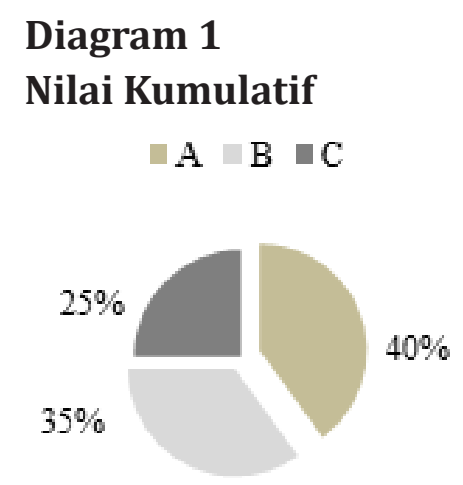

Sumber: Dokumentasi Pondok Pesantren

Kemudian peneliti membagi dua kategori nilai, (kategori tinggi dan rendah) pada nilai kumulatif hasil ujian-ujian gramatika pada semester ganjil, yaitu 86100 untuk kategori tinggi, dan 70-85 untuk kategori rendah.

\section{Diagram 2 \\ Kategori Nilai}

- Tinggi $\quad$ Rendah

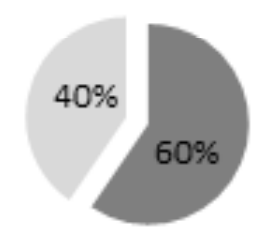

Tarbawiyah, Majalad 5, 'Adad 2, 2009 (diakses 20 Oktober 2013)

19 H. Douglas Brown, Teaching by Principles An Interactive Approach to Language Pedagogy, 421. 
Berdasarkan diagram di atas 60\% siswa mendapatkan kategori tinggi dengan nilai paling tinggi yaitu 99 artinya siswa mampu mengikuti pelajaran gramatika dalam kelas dan memperoleh hasil yang maksimal, sedangkan $40 \%$ siswa lainnya mendapat kategori rendah dengan nilai 77, dengan ratarata nilai 87. Berdasarkan hasil perhitungan nilai pada semester ganjil tersebut peserta didik cenderung banyak mendapatkan kategoritinggidalamkemampuanmemahami gramatika bahasa Arab.

Menurut peneliti ada beberapa faktor peserta didik cenderung mendapatkan kategori tinggi. Faktor yang pertama peserta didik tidak hanya mendapat sumpalan-sumpalan materi gramatika akan tetapi peserta didik juga sering mendapatkan tugas-tugas yang berkenaan dengan gramatika. Hal ini juga diperkuat oleh Tammâm Hassân. Menurut Tammâm persoalan utama dalam pembelajaran nahww adalah karena kurangnya pemberian latihan yang berkelanjutan (tadrîbât nahwiyah mustamirrah), seperti latihan menyusun kalimat sempurna (efektif) atau merubah kalimat fi'liyyah menjadi ismiyyah, tamrînat, dan sebagainya. Menurut Tammâm dengan latihan intensif pembelajar nahw tidak hanya dapat menirukan dan melibatkan diri dalam aktivitas berbahasa, melainkan juga dapat beradaptasi, menyesuaikan diri dengan kebiasaan-kebiasaan berbahasa Arab yang telah menjadi budaya Arab. ${ }^{20}$

Faktor yang kedua adalah peserta didik mempunyai semangat dan sikap yang positif terhadap pembelajaran gramatika bahasa Arab. Hal ini terbukti dari hasil sebaran kuisioner yang peneliti ajukan bahwa $95,45 \%$ peserta didik termotivasi

20 Tammâm Hassân, al-Lughah Baina alMi'yâriyyah, dalam Muhbib Abdul Wahab, Pemikiran Tammâm Hassân dalam Pembelajaran Bahasa Arab, h. 193 dalam pembelajaran gramatika. ${ }^{21}$ Menurut Suryabrata minat individu dan motivasi belajar merupakan faktor yang mempengaruhi belajar. ${ }^{22}$

Pazaver dan Hang Wang dalam penelitiannya menyatakan bahwa siswa memiliki berbagai persepsi tentang pengajaran gramatika beberapa siswa mengatakan gramatika sangat membantu dalam pembelajaran mereka beberapa lagi sangat membantu dalam penulisan. ${ }^{23}$ Vivian Cook membuktikan urgensi pelajaran gramatika dengan meneliti lulusan universitas di Eropa yang mempelajari tata bahasa secara tradisional hampir semuanya berpendapat bahwa pengajaran gramatika membantu dalam pengecekan tulisan. ${ }^{24}$

Persepsi positif ini juga terlihat dalam jawaban responden terhadap pembelajaran bahasa Arab. Seperti pernyataan dalam tabel berikut:

\section{Tabel 1}

\begin{tabular}{|l|l|l|l|l|l|}
\hline \multirow{2}{*}{ Pernyataan } & \multicolumn{5}{|l|}{ Jawaban Responden } \\
\cline { 2 - 6 } & S & SS & N & TS & STS \\
\hline $\begin{array}{l}\text { Saya berniat untuk } \\
\text { melanjutkan pendidikan } \\
\text { bahasa Arab saya }\end{array}$ & $\begin{array}{l}28,57 \\
\%\end{array}$ & $\begin{array}{l}28,57 \\
\%\end{array}$ & $\begin{array}{l}38,09 \\
\%\end{array}$ & $\begin{array}{l}4,76 \\
\%\end{array}$ & - \\
\hline
\end{tabular}

Keterangan: S: Setuju, SS: Sangat Setuju, N: Tidak Berpendapat, TS: Tidak Setuju, STS: Sangat Tidak Setuju

Tabel di atas menunjukkan bahwa peserta didik banyak berminat untuk melanjutkan pendidikan bahasa Arabnya.

21 Kuisioner di pondok pesantren selama proses penelitian berlangsung 28 Desember 2013 sampai 18 Februari 2014

22 Keke T. Aritonang, "Minat dan Motivasi dalam Meningkatkan Hasil Belajar Siswa”, Jurnal Pendidikan Penabur-No.10/Tahun ke-7/Juni 2008 (diakses 25 April 2014)

23 Anne Pazaver, Hong Wang, “Asian Students' Perceptions of Grammar Teaching in the ESL Classroom," The International Journal of Language Society and Culture, LSC-2009 ISSN 1327-774X, (accessed July 14, 2013)

24 Vivian Cook, Second Language Learning and Language Teaching, Fourth Edition(London: Hodder Education, 2008), h. 40. 
Hal ini adalah bagian dari motivasi terhadap mata pelajaran nahwu /sharf bahasa Arab. Mursell dalam bukunya Successfull Teaching, mengemukakan terdapat 22 macam minat yang salah satunya adalah bahwa anak memiliki minat terhadap belajar. ${ }^{25}$

Pada kemampuan performansi peneliti menilai dalam dua kegiatan yaitu kegiatan bercerita di dalam kelas dan diskusi kelas bebas. Beberapa aspek yang dinilai oleh peneliti yaitu: kejelasan pelafalan, kemampuan pemahaman kaidah gramatika, kefasihan, kesalahan sharf dan nahwu, pemilihan kosakata, ketepatan bentuk kalimat, performa (kontak mata, ekspresi wajah dan gestur), kelancaran berbicara, kemampuan penerapan kaidah gramatika dalam berbicara, aspek keseluruhan tata bahasa (nahwu dan sharf), gaya bahasa dan pengucapan.

\section{Grafik 1}

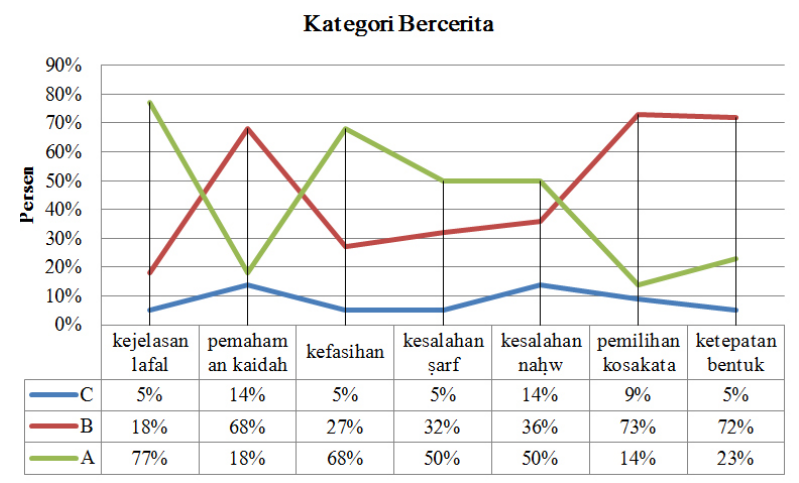

\section{Grafik 2}

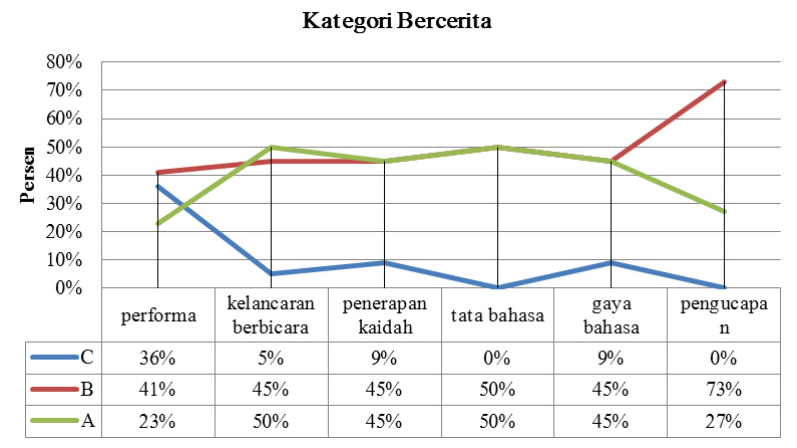

25 Mursell dalam Keke T. Aritonang, "Minat dan Motivasi dalam Meningkatkan Hasil Belajar Siswa”, Jurnal Pendidikan Penabur-No.10/Tahun ke-7/Juni 2008 (diakses 25 April 2014)
Jika dilihat kemampuan gramatika pada tabel diatas jumlah peserta didik yang mengalami sedikit kesalahan dari segi nahwu adalah 14\% dan sharf 5\%. Jumlah ini membuktikan bahwa $86 \%$ peserta didik sangat kompeten dalam bercerita berbahasa Arab dengan sedikit kesalahan gramatika.

Sebuah penelitian menyatakan pentingnya keterampilan bercerita dalam komunikasi adalah bahwa apabila seseorang memiliki keterampilan berbicara yang baik dia akan memperoleh keuntungan sosial maupun profesional. Keuntungan sosial berkaitan dengan kegiatan interaksi sosial antar individu. Sedangkan keuntungan profesional diperoleh sewaktu menggunakan bahasa untuk membuat pertanyaan-pertanyaan, menyampaikan fakta-fakta dan pengetahuan, menjelaskan dan mendeskripsikan. ${ }^{26}$

Penelitian dalam kategori kedua adalah diskusi kelas bebas, diskusi ini terdapat beberapa model yang dapat digunakan antara lain; diskusi kelas dua kelompok saling berhadapan, diskusi kelas bebas, diskusi kelompok dan diskusi panel. ${ }^{27}$ Pada penelitian ini peserta didik diminta untuk mempresentasikan makalah dengan waktu masing-masing tiga sampai lima menit, tema yang diangkat adalah sub judul pelajaran gramatika yang sudah dipelajari.

26 Supriyadi, "Pembelajaran Keterampilan Berbicara Melalui Pendekatan Pengalaman Berbahasa di Sekolah Dasar", Artikel Keterampilan Berbicara.

27 Muhammad Nur Asmawi, "Ta'bir Shafawi; Metode dan Teknik Pengajarannya", Jurnal Hunafa, Vol. 6 No. 3, Desember 2009 (diakses 14 Maret 2014) 


\section{Grafik 3}

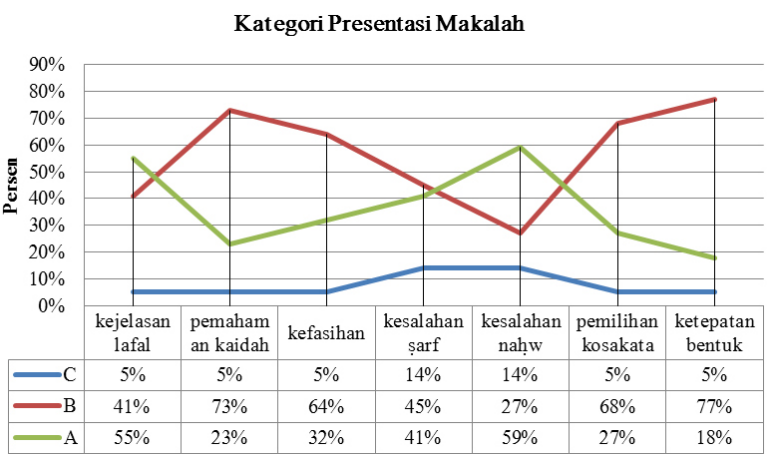

\section{Grafik 4}

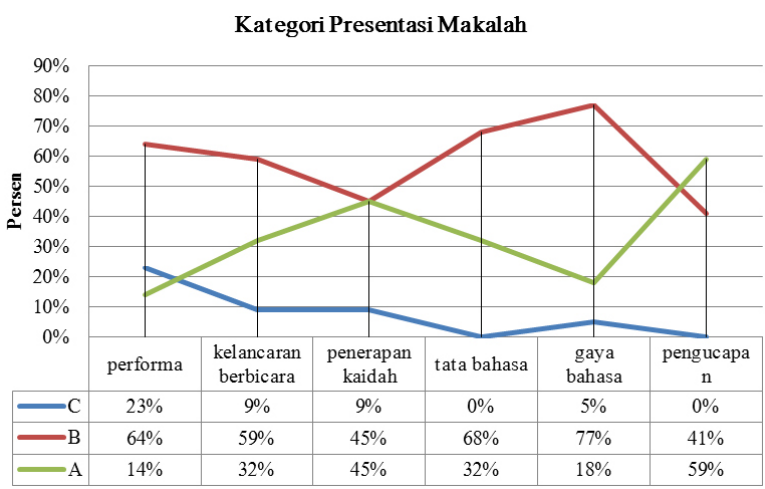

Dari beberapa aspek penilaian performansi gramatika yang telah dinilai maka didapatkan nilai kumulatif sebagai kesimpulan performansi gramatika melalui keterampilan berbicara.

\section{Grafik 5}

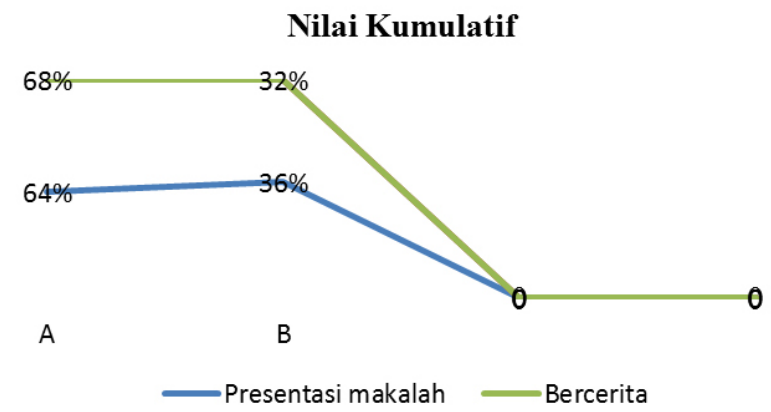

Dilihat dari tabel di atas bahwa pada aspek bercerita 68\% peserta didik lebih banyak mendapatkan nilai A. Artinya bahwa pembelajaran gramatika mampu membuat performa bahasa Arab peserta didik tidak ada atau sedikit kesalahan tata bahasa. 40\% peserta didik lainnya mendapatkan kategori nilai B yang artinya peserta didik kadang- kadang membuat kesalahan gramatika pada performa bahasa Arab.

Selanjutnya hubungan kemampuan gramatika secara formal terhadap kemampuan performa bahasa dapat dilihat sebagai berikut:

1. Skor performa 1 dan 2 peneliti uji dengan uji normalitas data kolmogorov dan smirnov melalui SPSS 16.

\section{Tabel 2}

Hasil Perhitungan Normalitas Data

\begin{tabular}{|l|l|}
\hline \multirow{2}{*}{ Variabel } & \multicolumn{1}{|c|}{ Uji normalitas } \\
\cline { 2 - 2 } & Kolmogorov-smirnov \\
\hline Skor performa 1 & 0.012 \\
\hline Skor performa 2 & 0.20 \\
\hline
\end{tabular}

Berdasarkan tabel, terlihat uji kolmogorov pada variabel Skor performa 1 yaitu nilai signifikan sebesar 0.012 dan variabel Skor performa 2 sebesar 0.20 , sedangkan syarat kenormalan data adalah Pvalue $>\alpha$. Ini berarti pada uji kolmogorov adalah Pvalue $<\alpha$ pada skor performa 1 , yaitu $0.012<0.05$ sehingga berdistribusi tidak normal, sedangkan skor performa 2 Pvalue $>\alpha$ yaitu $0.20>$ 0.05 sehingga berdistribusi normal.

2. Pada variabel skor performa 1 data tidak berdistribusi normal, maka perhitungan statistik menggunakan uji $\mathrm{T}$ nonparametrik. Adapun hasil perhitungan adalah sebagai berikut :

\section{Tabel 3}

\section{Hubungan antara Skor Gramatika dan Skor Performa 1}

\begin{tabular}{|l|l|l|}
\hline Skor Gramatika & Pvalue & N \\
\hline Tinggi & 0.081 & 13 \\
\cline { 3 - 3 } Rendah & & 9 \\
\hline
\end{tabular}

Pada tabel menunjukkan $\mathrm{N}$ skor gramatika yang tinggi adalah 13 siswa dan skor gramatika yang rendah siswa adalah 9 siswa. Berdasarkan uji statistik didapatkan nilai Pvalue adalah 0.018, 
artinya pada $(\mathrm{p}<$ ) ada hubungan yang signifikan antara skor performa 1 dan skor gramatika.

Pada variabel skor performa 2 data berdistribusi normal, maka perhitungan statistik menggunakan uji $\mathrm{T}$ parametrik. Adapun hasil perhitungan adalah sebagai berikut:

\section{Tabel 4}

\section{Hubungan antara Skor Gramatika dan} Skor Performa 2

\begin{tabular}{|l|l|l|}
\hline Skor Gramatika & Pvalue & N \\
\hline Tinggi & 0.069 & 13 \\
\cline { 1 - 1 } Rendah & & 9 \\
\hline
\end{tabular}

Pada tabel menunjukkan $\mathrm{N}$ skor gramatika yang tinggi adalah 13 siswa dan skor gramatika yang rendah adalah 9 siswa. Berdasarkan uji statistik didapatkan nilai Pvalue adalah 0.069 artinya pada ( $<$ ) ada perbedaan yang signifikan antara skor performa 2 dan skor gramatika.

Performansi merupakan cerminan kompetensi yang mana sebelumnya Krashen mengatakan bahwa pembelajaran gramatika tidak mempunyai peran dalam kualitas berbicara pada pembelajar. Pikiran dasar menurut Chomsky tentang kompetensi dan performansi adalah kompetensi yang ideal menghubungkan runtunan bunyi dengan isi semantiknya ini juga berarti menghubungkan runtutan berbahasa (performansi). Singkatnya, kompetensi adalah the speaker-hears knowledge of his language sedangkan performansi adalah the actual use of language in concrete situation. $^{28}$

Dari data yang dipaparkan di atas kemampuan performa ini juga dipengaruhi terhadap asumsi peserta didik terhadap mata pelajaran gramatika di kelas. Dapat

28 Noam Chomsky dalam Jos Daniel Parera, Dasar-Dasar Analisis Sintaksis (Jakarta: Erlangga, 2009) h.108 dilihat pada tabel berikut ini:

\section{Tabel 5}

\begin{tabular}{|l|c|c|c|c|}
\hline Pernyataan & TP & AP & CP & SP \\
\hline $\begin{array}{l}\text { Penguasaan bahasa } \\
\text { Arab dengan } n a \underline{h} w /\end{array}$ & & & & \\
sharf yang lebih baik & 14,28 & 9,52 & 42,85 & 28,57 \\
membuat saya lebih & $\%$ & $\%$ & $\%$ & $\%$ \\
mudah mendapat & & & & \\
pekerjaan dan beasiswa & & & & \\
\hline
\end{tabular}

\section{Keterangan:}

TP: Tidak Penting, AP: Agak Penting, CP: Cukup Penting, SP: Sangat penting

Dari data di atas, sikap yang positif terhadap mata pelajaran gramatika membuat peserta didik bersemangat untuk mempelajari gramatika. Keinginan untuk mendapatkan pekerjaan dan beasiswa membuat peserta didik menguasai gramatika dengan baik meskipun ada beberapa peserta didik yang belum tertarik untuk mempelajari nahwu/sharf .

\section{Simpulan}

Kemampuan performa ini ditunjang oleh beberapa hal: pertama, selain peserta didik mendapatkan materi pelajaran gramatika secara formal gramatika juga diajarkan secara ekstrakurikuler setelah ashar. Artinya, frekuensi pengajaran gramatika cukup tinggi. Kedua, bahasa pengantar pada aktivitas belajar mengajar adalah bahasa Arab yang membuat peserta didik terbiasa mendengar kalimat-kalimat yang benar dari guru bidang studi tersebut. Ketiga, lingkungan wajib berbahasa di mana peserta didik mendapatkan ilmu gramatika dan langsung diterapkan pada pemakaian bahasa sehari-hari di pesantren.

Brownmengatakanbahwapembelajaran gramatika secara eksplisit lebih efektif untuk tingkat sekolah menengah pertama dan sekolah menengah ke atas. ${ }^{29}$ Tiga hal

29 H. Douglas Brown, Teaching by Principles An Interactive Approach to Language Pedagogy (United States: Pearson Education, 2007) h. 421. 
inilah yang membuat pelajaran gramatika tidak terabaikan sebagaimana fungsi pembelajaran gramatika untuk menjadi acuan pembicara dalam melihat kalimatkalimat yang benar dan tidak terjadi salah paham terhadap lawan bicara.

Dapat disimpulkan bahwa pembelajaran gramatika mempunyai peran dalam meningkatkanperformabahasa.Kesimpulan ini membantah teori Krashen yang mengatakan bahwa pengajaran gramatika selama berjam-jam didalam kelas hanya menyebabkan sedikit peningkatan pada performa terutama pada tes tata bahasa dan dengan cepat pula dilupakan. ${ }^{30}$ Menurut peneliti pembelajaran gramatika untuk belajar bahasa kedua di sekolah adalah sesuatu yang penting karena perolehan gramatika tidak hanya bisa diperoleh secara alami melainkan harus diajari dan diajarkan secara formal.

Gramatika mempunyai hubungan yang signifikan dalam menentukan performansi bahasa yang sesuai dalam aturan-aturan kaidah berbahasa. Pembelajaran gramatika tentu harus diajarkan dalam kelas bahasa kedua sebagai bahasa asing karena gramatika tidak dapat diperoleh begitu saja melalui komunikasi [].

\section{Daftar Rujukan}

Abdul Wahab, Muhbib. Epistemologi \& Metodologi Pembelajaran Bahasa Arab. Jakarta: Lembaga Penelitian Universitas Islam Negeri Syarif Hidayatullah Jakarta, 2008.

30 Stephen Krashen, "Seeking a Role for Grammar: A Review of Some Recent Studies," Foreign Language Annals, vol. 32, no. 2, (accessed July 12, 2014) lihat juga Stephen Krashen, Second Language Acquisition and Second Language Learning (New York: Prentice-Hall) Available for free downloading at http://www.sdkrashen.com
Abdul Wahab, Muhbib. Pemikiran Linguistik Tammam Hassan dalam Pembelajaran Bahasa Arab, Jakarta: UIN Jakarta Press, 2009.

Abdul Chaer. Psikolingustik Kajian Teoritik. Jakarta: Rineka Cipta, 2009.

Amin Al-Kukhun, dan Linâ Haniyah. "Atharu Istikhdam ad-Dirâma at-Ta'lîmiyah fî Tadrîsi Qawâ'id al-Lughah al-'Arabiyah fi Tahșili Ṭ̂alibāh aș-Ṣafi al-Âshir alAsâsî." Majallah al-Urduniyah fî 'Ulumi at-Tarbawiyah, Majalad 5, 'Adad 2, 2009. (diakses 20 Oktober 2013).

Aritonang, Keke T. "Minat dan Motivasi dalam Meningkatkan Hasil Belajar Siswa." Jurnal Pendidikan PenaburNo.10/Tahun ke-7/Juni 2008. (diakses 25 April 2014).

Bates, Elizabeth. On The Nature and Nurture of Language. San Diego: University of California. (accessed July 03, 2014).

Brown, H. Douglas. Teaching by Principles An Interactive Approach to Language Pedagogy. United States: Pearson Education, 2007.

Cook, Vivian. Second Language Learning and Language Teaching. Fourth Edition. London: Hodder Education, 2008.

Chomsky, Noam. On Nature and Language. Cambridge: Cambridge University Press, 2002.

Dardjowidjojo, Soenjono. Psikolinguistik Pengantar Pemahaman Bahasa Manusia. Jakarta: Yayasan Obor Indonesia, 2010.

Krashen, Stephen D. "The Effect of Formal Grammar Teaching: Still Peripheral." TESOL QUARTERLY Volume 27, No.4 (Winter 1993). (accessed July 1, 2013).

Krashen, Stephen. "Seeking a Role for Grammar: A Review of Some Recent Studies." Foreign Language Annals, vol. 
32, no. 2. (accessed July 12, 2014).

Krashen, Stephen. Second Language Acquisition and Second Language Learning. New York: Prentice-Hall. Available for free downloading at http:// www.sdkrashen.com.

Mahmoud, Abdulmoneim. "Learner Involvement in Language Development: From Course Design to Performance Assessment." Journal of Language Teaching and Research, Vol. 4, No. 4, July 2013. (accessed October 30, 2013).

Nur Asmawi, Muhammad. “Ta'bir Shafawi; Metode dan Teknik Pengajarannya." Jurnal Hunafa, Vol. 6 No. 3, Desember 2009. (diakses 14 Maret 2014).

Parera, Jos Daniel. Linguistik Edukasional Metodologi Pembelajaran Bahasa Analisis Konstranstif Antarbahasa Analisis Kesalahan Berbahasa. Jakarta: Erlangga, 1997. Parera, Jos Daniel. Dasar-Dasar Analisis Sintaksis. Jakarta: Erlangga, 2009.

Pazaver, Anne. Hong Wang. “Asian Students' Perceptions of Grammar Teaching in the ESL Classroom." The International Journal of Language Society and Culture, LSC-2009 ISSN 1327-774X. (accessed July 14, 2013).
Purpura, James. Assessing Grammar. Australia: Cambridge University Press, 2004.

Supriyadi. "Pembelajaran Keterampilan Berbicara Melalui Pendekatan Pengalaman Berbahasa di Sekolah Dasar." Artikel Keterampilan Berbicara.

Shinin, Bulkhair. “Turuqu Tadrîs al-Qawā'id an-Nahhwwiyah wa 'Alaqatuhā bi Fikri Ibnu Khaldûn." Majalah al-Athar, al'Adad 13 / Māris 2012. (diakses 20 Oktober 2013).

Skinner, B. F. Verbal Behavior. Harvard: Harvard University, 1948. (accessed July 04, 2014).

Zhang, Jianyun. "Necessity of Grammar Teaching." International Education Studies Vol. 2 No. 2 (May 2009). (accessed May 21, 2013). 